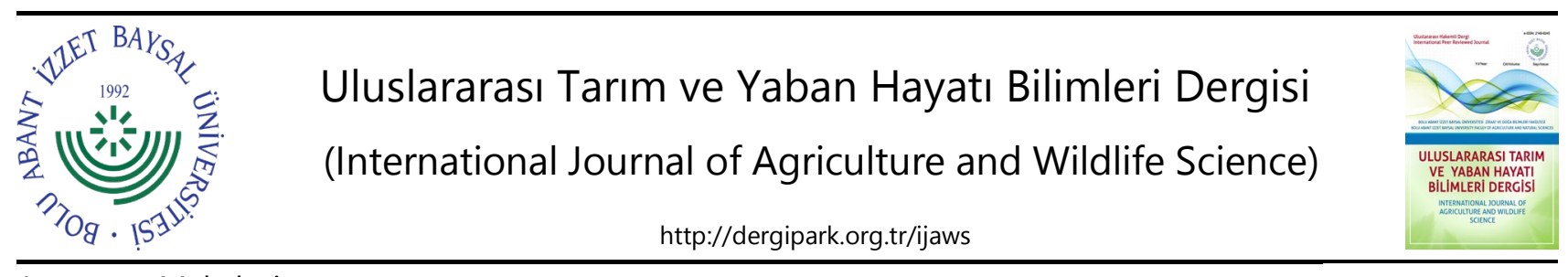

Araştırma Makalesi

\title{
Kivi Meyvelerinin Olgunlaşma Evrelerine Göre Fenolik Bileşik İçeriklerindeki Dağılım
}

\author{
Melek Şahin Kanbur, Muttalip Gündoğdu* \\ Bolu Abant İzzet Baysal Üniversitesi, Ziraat Fakültesi, Bahçe Bitkileri Bölümü, Bolu \\ Geliş tarihi (Received): 21.05.2020Ｋabul tarihi (Accepted): 17.06.2020
}

\begin{abstract}
Anahtar kelimeler:
Fenolik, kivi, olgunlaşma

*Sorumlu yazar

gundogdumuttalip@gmail.com

Özet. Kivi, zengin biyokimyasal içeriğe sahip olması, aroma ve tad bakımından tercih edilen meyve türleri arasında yer alması meyve pazarında arz talep dengesini pozitif yönde etkilemektedir. Dolayısı ile bu meyve türünün popülaritesi gün geçtikçe artmaktadır. Olgunluk kriterlerine göre meyvelerin biyokimyasal içeriğinde değişimlerin olduğu bilinen bir gerçeketir. Bu doğrultuda, yapılan çalışmada toplam 12 fenolik bileşik iki farklı dönemde (1. dönem: hasat olumundan bir ay önce ve 2. Dönem: hasat olumu) alınan meyve örneklerinde incelenmiştir. Bu araştırmada, 1. dönem meyvelerinin gallik asit içeriği $0.408 \mathrm{mg} 100 \mathrm{~g}^{-1}$ (Hayward)- $0.256 \mathrm{mg} 100 \mathrm{~g}^{-1}$ (Bruno) arasında tespit edilmiş ve 2. dönem meyvelerinde ise $0.655 \mathrm{mg} 100 \mathrm{~g}^{-1}$ (Monty)- $0.164 \mathrm{mg} 100 \mathrm{~g}^{-1}$ (Bruno) arasında belirlenmiştir. Protokateşuik asit içeriği 1. dönem meyvelerinde $0.237 \mathrm{mg} 100 \mathrm{~g}^{-1}$ (Hayward)- $0.067 \mathrm{mg} 100 \mathrm{~g}^{-1}$ (Greenlight) arasında ve 2. dönem meyvelerinde ise $0.221 \mathrm{mg} 100 \mathrm{~g}^{-1}$ (Hayward)- $0.035 \mathrm{mg} 100 \mathrm{~g}^{-1}$ (Greenlight) değerleri arasında kaydedilmiştir. Fenolik bileşiklerden kateşin, klorojenik asit, vanilik asit, kaffeik asit, siyringik asit, p-kumarik asit, ferulik asit, o-kumarik asit, rutin ve kuersetin içerikleri de ayrıca tespit edilmiştir.
\end{abstract}

\section{Distribution of Phenolic Compounds Content According to the Maturity Stages of Kiwi Fruits}

\author{
Keywords: \\ Phenolic, kiwi, maturity
}

\begin{abstract}
Kiwi, having a rich biochemical content, being among the fruit types preferred in terms of flavor and taste, positively affects the supply-demand balance in the fruit market. Therefore, the popularity of this fruit species is increasing day by day. It is a known fact that there are changes in the biochemical content of fruits according to the maturity criteria. Accordingly, in the study, a total of 12 phenolic compounds were examined in fruit samples taken in two different stages (1st stage: one month before harvest and 2nd stage: harvest maturity). In this study, the gallic acid content of the 1st

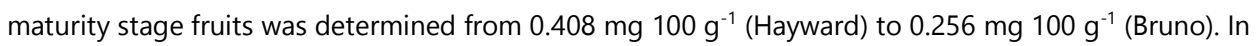
the fruits of the $2 \mathrm{nd}$ maturity satage, the gallic acid content was determined from $0.655 \mathrm{mg}^{100 \mathrm{~g}^{-1}}$

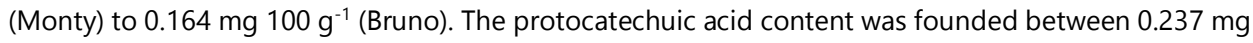
$100 \mathrm{~g}^{-1}$ (Hayward) - $0.067 \mathrm{mg} 100 \mathrm{~g}^{-1}$ (Greenlight) in 1st maturity stage fruits and it was recorded between $0.221 \mathrm{mg} 100 \mathrm{~g}-1$ (Hayward) - $0.035 \mathrm{mg} 100 \mathrm{~g}^{-1}$ (Greenlight) in 2nd maturity stage fruits. The contents of catechin, chlorogenic acid, vanicic acid, caffeic acid, syringic acid, p-coumaric acid, ferulic acid, o-coumaric acid, routine and quercetin were also determined.
\end{abstract}




\section{GíRiş}

Alternatif meyvelerin arayışı insanların istek ve taleplerindeki rutin durumu modifiye etmek istemesi nedeniyle hız kazanmıştır. Bu doğrultuda kivi son yıllarda yetiştiriciliği ve üretimi artan meyveler arasında yer almaktadır. Dünyada en fazla yetiştiriciliği yapılan kivi çeşitlerinin bir kısmı Actinidia deliciosa türünde yer almakta ve bu çeşitler türün yayılışını pozitif yönde etkilemektedir (Ferguson ve Bollard, 1990). Çin'de yapılan çalışmalarda Actinidia cinsine ait 57 adet tür bildirilerek bunlardan ekonomik potansiyeli olan ve en iyi olanlarının A.chinensis ve A.deliciosa olduğu belirtilmiştir (Ming ve ark., 1991). Kivi çeşitleri arasında yer alan Hayward çeşidi ülkemizde de yetiştirilen kivinin büyük bir kısmını oluşturmaktadır. Fakat İtalya ve Yeni Zelanda gibi ülkelerde erkenci kivi çeşitleri ve Actinidia chinensis türüne ait sarı meyve etine sahip kivi çeşitleri popülerlik kazanmıştır (Yalçın, 1999). Ülkemizde kivi üretiminin büyük bir bölümünü Yalova (21.535 ton) ilimiz sağlamaktadır. Bunu sırayla Rize (5.554 ton), Ordu (4.841 ton), Samsun (2.337 ton) ve Trabzon (2.035 ton) illerimiz takip etmektedir (TÜiK, 2018). Fenolik bileşikler, hidroksibenzoik (protokateşik ve vanilik asit) ve hidroksisinnamik (kafeik, klorojenik, p-kumarik ve sinnamik asit) asitlerden oluşmaktadır. Meyvenin bünyesinde, flavonol (kamferol, kuersetin) ve flavanon (naringenin) bileşenlerinin mevcut olduğu belirtilmektedir (Pınellı ve ark., 2013; Shehata ve ark., 2013). Kivi meyvesinin, vücutta endojen antioksidan olarak L-sistein, L-glutamik asit ve glisin aminoasitlerinden sentezlenen glutatyon (225 $\mathrm{g} \mathrm{g} \mathrm{g}^{-1}$ ) tripeptidini ihtiva etmekte olduğu bildirilmektedir (Witschı ve ark., 1992). Kivi meyvesinde, vücuda canlılık ve zindelik sağlayarak aynı zamanda duygu durum ve davranış üzerinde etkili olarak, ruh halini iyileştiren nörotransmitter serotonin $\left(6 \mu \mathrm{g} \mathrm{g}^{-1}\right.$ ) bulunduğu ifade edilmektedir (Herraız ve Galısteo, 2003). Kivi meyvesi yapısındaki fitokimyasallara göre 3.84-13.03 $\mu \mathrm{mol} \mathrm{g}{ }^{-1}$ aralığında antioksidan kapasiteye (oksijen radikal absorbans kapasiteye (ORAC)) sahip olduğu bildirilmektedir (USDA, 2018b). Yapılan araştırmalarda kivi meyvesinin içerdiği zengin biyokimyasal içeriği sayesinde bir çok hastalığa (kolesterol düşürücü, çocuklarda kemik ve beyin gelişimini arttırıcı, trigliserit düşürücü, bağışıklık sistemini kuvvetlendirici, bağırsak florasını düzenleyici etkilerinin yanında antioksidan, antikanserojen, antimutajenik, antiinflamatuvar, antidiyabetik, antimikrobiyal, antikonstipasyon, antitrombotik, sitotoksik, hepatoprotektif özelliklerinin beraberinde astım, kardiyovasküler hastalıklar) karşı koruyucu ve tedavi edici etkiye sahip olduğu ifade edilmektedir (Herraız ve Galısteo, 2003; Funk ve ark., 2007; Hunter ve ark., 2010; Salıyan ve ark., 2017; Sıngletary, 2012; Stonehouse ve ark., 2015).

Taze tüketimi yaygın olan kivi meyvesi, kurutularak, dondurularak, gıda endüstrisinde meyve suyuna işlenerek, reçel, marmelat, pasta, dondurma ve ilaç sanayisinde de oldukça fazla kullanım alanı olan bir meyvedir. Ayrıca $C$ vitaminince zengin içeriğe sahip olması ve kalori içeriğinin düşük olmasından dolayı sağlıklı beslenme bakımından fazlaca önemli bir meyve türüdür. Bunun yanı sıra kivinin birçok hastalığın tedavisinde ya da önlenmesinde etkin rol alması nedeniyle üretimi ve tüketimi yıldan yıla artış göstermektedir. Kivi meyvesi, antimutajenik etkiye sahip bir besin olduğu için fonksiyonel gıda olarak tüketilmesi gereken meyvelerden biridir. Bu nedenle çalışmamızda, Yalova koşullarında yetiştiriciliği yapılan "Hayward, Bruno, Monty, Greenlight ve Topstar" kivi çeşitlerinin iki farklı dönemde (hasat olumu ve hasat olumundan bir ay önce) alınan meyve örneklerinin içerdiği spesifik fenolik bileşik içeriklerinin tespit edilmesi ve bu bağlamda kivi meyvesinin sağlıklı beslenmedeki yerinin ne denli önemli olduğunun vurgulanması amaçlanmıştır. Ayrıca meyvelerin farklı olgunluk dönemlerinde fenolik bileşik içeriklerindeki değişimin nasıl gerçekleştiği ve dağılımın olgunluk evreleri ile arasındaki korelasyonda incelenmiştir.

\section{MATERYAL VE METOT}

Yapılan araştırmada, ülkemizde yoğun olarak yetiştiriciliği yapılan Hayward, Bruno, Monty, Greenlight ve Topstar kivi çeşitleri kullanılmıştır. Yalova'da yetiştirilen bu çeşitlerin meyveleri İki farklı dönemde hasat edilmiş ve örnekler 1. ve 2. dönem olarak sınıflandırılmıştır. 1. dönem; hasat olumundan bir ay önceki dönem ve 2.dönem; hasat olumu dönemi olarak ifade edilmiştir. Alınan örnekler laboratuvara getirilerek ekstraksiyon işlemleri yapılmıştır. Araştırmada gallik asit, protokateşuik asit, kateşin, klorojenik asit, kaffeik asit, p-kumarik asit, ferulik asit, 0-kumarik asit, vanilik, rutin, siringik ve kuersetin fenolik bileşikleri tespit edilmiştir. Fenolik bileşiklerin HPLC ile ayrılmasında Rodriguez-Delgado ve ark. (2001) tarafından belirlenen yöntem kullanılmıştır. $5 \mathrm{~g}$ kivi örneği homojenizatörde parçalandıktan sonra 1:1 oranında distile su ile sulandırıldı ve 15 dk. 15000 rpm'de santrifüj edilmiştir. Santrifüj tüpünde üstte kalan kısım $0.45 \mu \mathrm{m}$ millipor filtrelerle filtre edildi ve HPLC'ye enjekte rdilmiştir.

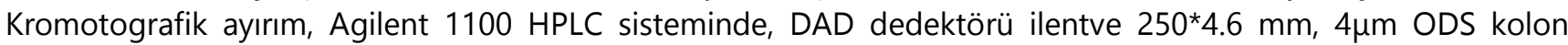
kullanılarak belirlenmiştir. Mobil faz olarak çözücü A Metanol-asetik asitsu (10:2:88), Çözücü B Metanol-asetik asit-su (90:2:8) kullanılmış ve gradient elusyon programı uygulanmıştır. Ayırım 254 ve $280 \mathrm{~nm}$ de gerçekleştirilmiş, akış hızı $1 \mathrm{~mL} \mathrm{dk}^{-1}$ ve enjeksiyon hacmi $20 \mu \mathrm{L}$ olarak belirlenmiştir. 


\section{Istatistiksel Analiz Veriler}

Windows SPSS 20 paket programında istatistiksel analize tabi tutulmuş ve farklılıkları belirlemek için Duncan çoklu karşılaştırma testi kullanılmıştır. Fenolik bileşik içerikleri arasındaki ilişkiyi belirlemek için temel bileşen analizinde (PCA) XLSTAT 2016 (Addinsoft, New York, ABD) programı kullanılmıştır.

\section{BULGULAR VE TARTIŞMA}

Yapılan araştırmada incelenen kivi çeşitlerine ait meyve sularında gallik asit, protokatşuik asit, kateşin, klorojenik asit, vanilik asit, kaffeik asit, siyringik asit, p-kumarik asit, ferulik asit, o-kumarik asit, rutin, kuersetin olmak üzere toplam 12 farklı fenolik bileşik HPLC ile belirlenmiştir. Çalışmada fenolik bileşiklerin incelenen çeşitlere göre değişim farklılığı istatistiksel olarak önemli seviyede bulunmuştur. Çizelge 1'deki değerlere göre kivi çeşitlerinin gallik asit miktarları bakımından farklııkları istatistiksel olarak önemli seviyede bulunmuştur. 1. dönem hasad edilen meyvelerde gallik asit miktarları, en yüksek Hayward (0.408 mg $\left.100 \mathrm{~g}^{-1}\right)$ çeşidinde ölçülürken, en düşük gallik asit değeri Bruno $\left(0.256 \mathrm{mg} 100 \mathrm{~g}^{-1}\right)$ çeşidinde ölçülmüştür. Araştırmada 2. dönem en yüksek gallik

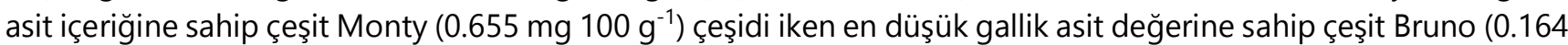
$\mathrm{mg} 100 \mathrm{~g}^{-1}$ ) çeşidi olarak saptanmıştır. Dönemler arasındaki fark çeşide bağlı olarak değişkenlik göstermiştir. Hayward ve Bruno çeşitlerinde 2. dönem gallik asit miktarı azalırken, diğer çeşitlerde artmıştır. Çizelge 1'e göre protokateşuik asit içeriği bakımından çeşitler arasındaki farklılıkların istatistiksel olarak önemli seviyede olduğu belirlenmiştir. Çalışmada protokateşuik asit düzeyleri incelendiğinde, 1. dönem en yüksek değere $0.237 \mathrm{mg} 100$

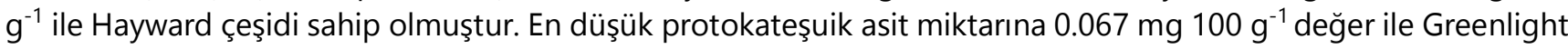
çeşidi sahip olmuştur. Araştırmada 2. dönem en yüksek protokateşuik asit içeriğine Hayward çeşidi 0.221 mg 100 $\mathrm{g}^{-1}$ değer ile sahip olurken (Şekil 1), en düşük protokateşuik asit içeriğine $0.035 \mathrm{mg} 100 \mathrm{~g}^{-1}$ değer ile Greenlight çeşidinin sahip olduğu kaydedilmiştir. Bruno ve Monty çeşitlerinde hasat olgunluğuna gelen meyvelerde protokateşuik asit miktarı artarken, diğer çeşitlerde erken hasat edilen meyvelerde daha yüksek olmuştur. Incelenen 5 çeşidin kateşin içeriklerine bakıldığında farklılıklar istatistiksel olarak önemli bulunmuştur. Yapılan araştırmada, 1. dönem en yüksek kateşin içeriğine sahip çeşit Bruno $\left(1.079 \mathrm{mg} 100 \mathrm{~g}^{-1}\right)$ çeşidi iken en düşük kateşin miktarına sahip çeşit Topstar $\left(0.829 \mathrm{mg} 100 \mathrm{~g} \mathrm{~g}^{-1}\right)$ çeşidi olarak saptanmıştır. Araştırmada 2. dönem en yüksek kateşin içeriğine sahip çeşit Topstar (1.065 mg $100 \mathrm{~g}^{-1}$ ) çeşidi iken en düşük kateşin değerine sahip çeşit Monty $\left(0.522 \mathrm{mg} 100 \mathrm{~g} \mathrm{~g}^{-1}\right)$ çeşidi olarak tespit edilmiştir. Topstar çeşidi hariç olmak kaydı ile, kateşin miktarı 2. dönem hasat edilen meyvelerde azalma göstermiştir. İncelenen kivi çeşitlerinin meyve suyunda klorojenik asit içeriklerine bakıldığında farklılıklar istatistiksel olarak önemli bulunmuştur. Yapılan çalışmada çeşitler arasında 1. dönem en yüksek klorojenik asit değeri Hayward çeşidinde $0.435 \mathrm{mg} 100 \mathrm{~g}^{-1}$ olarak ölçülmüştür. Greenlight çeşidi ise 0.214 mg $100 \mathrm{~g}^{-1}$ değer ile en düşük klorojenik asit içeriğine sahip çeşit olarak kaydedilmiştir. 2. dönem en yüksek klorojenik asit miktarı Hayward çeşidinde $0.418 \mathrm{mg} 100 \mathrm{~g}^{-1}$ olarak ölçülmüştür (Şekil 4.8). Bu dönemde en düşük klorojenik asit miktarına sahip çeşit ise Greenlight $\left(0.221 \mathrm{mg} 100 \mathrm{~g}^{-1}\right)$ çeşidi olarak belirlenmiştir. Klorojenik asit miktarı 2.dönem hasad edilen meyvelerde, Topstar ve Greenlight çeşitleri hariç olmak üzere, azalma göstermiştir. Bu çeşitlerdeki artışın ise çok az miktarlarda olduğu görülmektedir (Çizelge 1).

Çizelge 2'ye göre meyve suyunda vanilik asit içeriği incelendiğinde farklılıklar istatistiksel olarak önemli bulunmuştur. İncelenen çeşitler arasında 1. dönem en yüksek vanilik asit içeriğine Bruno $\left(0.094 \mathrm{mg} 100 \mathrm{~g}^{-1}\right)$ çeşidi

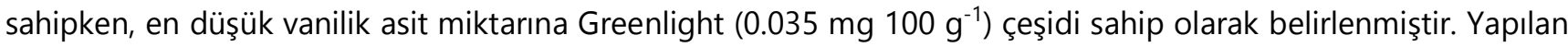
çalışmada 2. dönem en yüksek vanilik asit içeriği Hayward $\left(0.057 \mathrm{mg}_{\left.100 \mathrm{~g}^{-1}\right)}\right)$ çeşidinde tespit edilmiştir. Aynı

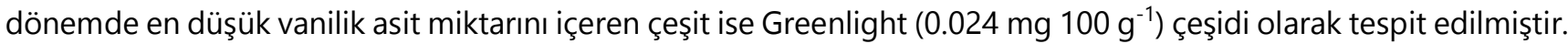
Hasat olgunluğuna gelen meyvelerde (2. dönem) vanillik asit miktarı belirgin bir şekilde azalma göstermiştir. Incelenen 5 kivi çeşidinde kafeik asit değerleri açısından çeşitler karşılaşıııılığında, istatistiksel olarak farklılıklar önemli görülmüştür. Kafeik asit içeriği açısından çeşitlere bakıldığında, 1. dönem en yüksek kafeik asit miktarına sahip çeşit Hayward $\left(0.869 \mathrm{mg} 100 \mathrm{~g}^{-1}\right)$ çeşidi iken, en düşük kafeik asit içeriğine sahip çeşit Monty (0.407 mg 100 $\mathrm{g}^{-1}$ ) çeşidi olarak saptanmıştır. Yapılan araştırmada 2. dönem en yüksek kafeik asit içeriğine sahip çeşit Hayward

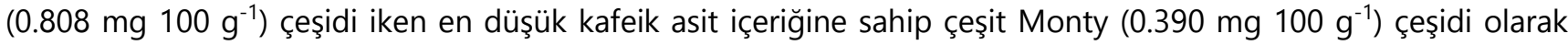
tespit edilmiştir. Kafeik asit miktarı 2. dönem hasat edilen meyvelerde 1. dönem hasat edilen meyvelere göre daha az olmuştur. Rutin içeriği bakımından incelenen çeşitler arasında oluşan farklılıklar istatistiksel olarak önemli seviyede bulunmuştur. Araştırmada rutin düzeyi bakımından çeşitler birbiriyle kıyaslandığında, Hayward $(0.106$ mg $100 \mathrm{~g} \mathrm{~g}^{-1}$ ) çeşidi 1 . dönem en yüksek rutin içeriğine sahip çeşit iken en düşük değere sahip çeşit Monty $(0.045$ mg $100 \mathrm{~g}^{-1}$ ) çeşidi olarak belirlenmiştir. Çalışmada 2. dönemde de en yüksek rutin miktarına sahip çeşit yine

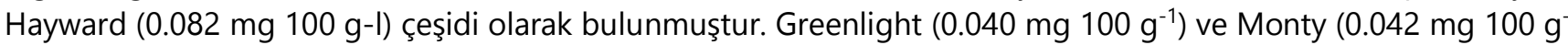


$\left.{ }^{1}\right)$ çeşitleri ise en düşük rutin içeriğine sahip çeşitler olarak tespit edilmiştir. Rutin miktarı geç hasat edilen meyvelerde (2. dönem), tüm çeşitlerde azalmıştır. İncelenen çeşitler kuersetin içerikleri bakımından karşılaştırıldığında oluşan farklılıkların istatistiksel olarak önemli olduğu belirlenmiştir. Yapılan çalışmada çeşitler kıyaslandığında; 1. dönem en yüksek kuersetin miktarına sahip olan çeşit Hayward $\left(0.516 \mathrm{mg} 100 \mathrm{~g} \mathrm{~g}^{-1}\right)$ çeşidi iken,

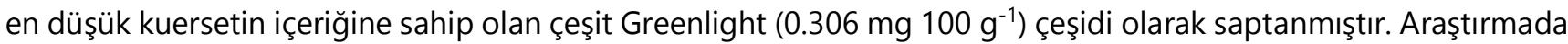

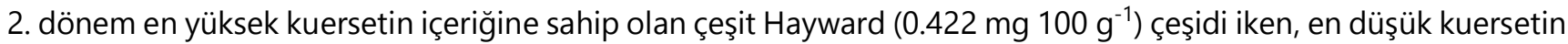
değerine sahip olan çeşit Topstar $\left(0.256 \mathrm{mg} 100 \mathrm{~g} \mathrm{~g}^{-1}\right)$ çeşidi olarak tespit edilmiştir. Kuersetin miktarı, tüm çeşitlerde hasat olgunluğuna gelen meyvelerde belirgin şekilde azalma göstermiştir.

Çizelge 1. Farklı olgunluklarda hasat edilen kivi meyvelerinin fenolik bileşik içerikleri-1 ( $\left.\mathrm{mg} 100 \mathrm{~g}^{-1}\right)$.

Table 1. Phenolic compound contents of kiwi fruit harvested in different maturity-1 ( $\mathrm{mg}^{\left.100 \mathrm{~g}^{-1}\right) \text {. }}$

\begin{tabular}{clcccc}
\hline Hasat Tar. & Çeşitler & \multicolumn{1}{c}{ Gallik asit } & Protokateşuik asit & Kateşin & Klorojenik asit \\
\hline \multirow{6}{*}{ 1. Dönem } & Hayward & $0.408 \pm 0.021 \mathrm{c}^{*}$ & $0.237 \pm 0.019 \mathrm{a}$ & $0.955 \pm 0.022 \mathrm{c}$ & $0.435 \pm 0.010 \mathrm{a}$ \\
& Bruno & $0.256 \pm 0.027 \mathrm{~g}$ & $0.122 \pm 0.022 \mathrm{~d}$ & $1.079 \pm 0.011 \mathrm{a}$ & $0.317 \pm 0.015 \mathrm{~d}$ \\
& Topstar & $0.120 \pm 0.016 \mathrm{i}$ & $0.133 \pm 0.011 \mathrm{~cd}$ & $0.829 \pm 0.020 \mathrm{f}$ & $0.270 \pm 0.008 \mathrm{ef}$ \\
& Monty & $0.392 \pm 0.047 \mathrm{~d}$ & $0.107 \pm 0.018 \mathrm{e}$ & $0.872 \pm 0.040 \mathrm{e}$ & $0.409 \pm 0.029 \mathrm{~b}$ \\
& Greenligh & $0.282 \pm 0.027 \mathrm{f}$ & $0.067 \pm 0.033 \mathrm{f}$ & $0.972 \pm 0.031 \mathrm{bc}$ & $0.214 \pm 0.015 \mathrm{~g}$ \\
& Hayward & $0.335 \pm 0.011 \mathrm{e}$ & $0.221 \pm 0.010 \mathrm{~b}$ & $0.912 \pm 0.028 \mathrm{~d}$ & $0.418 \pm 0.010 \mathrm{ab}$ \\
& Bruno & $0.164 \pm 0.028 \mathrm{~h}$ & $0.142 \pm 0.019 \mathrm{c}$ & $0.978 \pm 0.030 \mathrm{~b}$ & $0.259 \pm 0.019 \mathrm{f}$ \\
& Topstar & $0.418 \pm 0.017 \mathrm{c}$ & $0.126 \pm 0.015 \mathrm{~d}$ & $1.065 \pm 0.035 \mathrm{a}$ & $0.278 \pm 0.027 \mathrm{e}$ \\
& Monty & $0.655 \pm 0.043 \mathrm{a}$ & $0.126 \pm 0.012 \mathrm{~d}$ & $0.522 \pm 0.027 \mathrm{~g}$ & $0.379 \pm 0.025 \mathrm{c}$ \\
& Greenligh & $0.488 \pm 0.043 \mathrm{~b}$ & $0.035 \pm 0.008 \mathrm{~g}$ & $0.815 \pm 0.024 \mathrm{f}$ & $0.221 \pm 0.010 \mathrm{~g}$ \\
\hline
\end{tabular}

*: Aynı sütun içersinde aynı harfle gösterilen ortalamalar arasındaki fark 0.05 seviyesinde önemli değildir.

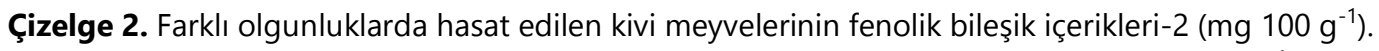
Table 2. Phenolic compound contents of kiwi fruit harvested in different maturity-2 ( $\left.\mathrm{mg} 100 \mathrm{~g}^{-1}\right)$.

\begin{tabular}{llcccc}
\hline Hasat Tarihleri & Çeşitler & Vanilik asit & Kaffeik asit & Rutin & Kuersetin \\
\hline \multirow{4}{*}{ 1. Dönem } & Hayward & $0.083 \pm 0.003 \mathrm{~b}^{*}$ & $0.869 \pm 0.021 \mathrm{a}$ & $0.106 \pm 0.008 \mathrm{a}$ & $0.516 \pm 0.010 \mathrm{a}$ \\
& Bruno & $0.094 \pm 0.006 \mathrm{a}$ & $0.520 \pm 0.018 \mathrm{~g}$ & $0.066 \pm 0.015 \mathrm{~d}$ & $0.348 \pm 0.016 \mathrm{~d}$ \\
& Topstar & $0.071 \pm 0.010 \mathrm{c}$ & $0.616 \pm 0.019 \mathrm{e}$ & $0.094 \pm 0.013 \mathrm{~b}$ & $0.423 \pm 0.029 \mathrm{c}$ \\
& Monty & $0.042 \pm 0.011 \mathrm{e}$ & $0.407 \pm 0.017 \mathrm{hi}$ & $0.045 \pm 0.004 \mathrm{f}$ & $0.464 \pm 0.020 \mathrm{~b}$ \\
& Greenlight & $0.035 \pm 0.007 \mathrm{f}$ & $0.722 \pm 0.008 \mathrm{c}$ & $0.054 \pm 0.007 \mathrm{e}$ & $0.306 \pm 0.018 \mathrm{e}$ \\
& Hayward & $0.057 \pm 0.003 \mathrm{~d}$ & $0.808 \pm 0.015 \mathrm{~b}$ & $0.082 \pm 0.011 \mathrm{c}$ & $0.422 \pm 0.016 \mathrm{c}$ \\
& Bruno & $0.042 \pm 0.001 \mathrm{e}$ & $0.417 \pm 0.010 \mathrm{~h}$ & $0.052 \pm 0.009 \mathrm{e}$ & $0.275 \pm 0.007 \mathrm{fg}$ \\
& Topstar & $0.028 \pm 0.002 \mathrm{gh}$ & $0.578 \pm 0.011 \mathrm{f}$ & $0.058 \pm 0.006 \mathrm{e}$ & $0.256 \pm 0.010 \mathrm{~g}$ \\
& Monty & $0.032 \pm 0.001 \mathrm{fg}$ & $0.390 \pm 0.016 \mathrm{i}$ & $0.042 \pm 0.003 \mathrm{f}$ & $0.362 \pm 0.017 \mathrm{~d}$ \\
& Greenlight & $0.024 \pm 0.003 \mathrm{~h}$ & $0.648 \pm 0.025 \mathrm{~d}$ & $0.040 \pm 0.007 \mathrm{f}$ & $0.296 \pm 0.020 \mathrm{ef}$ \\
\hline
\end{tabular}

*: Aynı sütun içerisinde aynı harfle gösterilen ortalamalar arasındaki fark 0.05 seviyesinde önemli değildir.

Çizelge 3. Farklı olgunluklarda hasat edilen kivi meyvelerinin fenolik bileşik içerikleri-3 (mg $\left.100 \mathrm{~g}^{-1}\right)$.

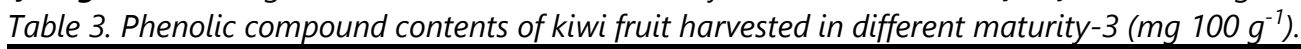

\begin{tabular}{llcccc}
\hline Hasat Tarihleri & Çeşitler & Siringik asit & p-Kumarik asit & Ferulik asit & o-kumarik asit \\
\hline \multirow{4}{*}{ 1. Dönem } & Hayward & $0.104 \pm 0.013 \mathrm{~b}^{*}$ & $0.114 \pm 0.009 \mathrm{~b}$ & $0.084 \pm 0.017 \mathrm{~b}$ & $0.064 \pm 0.009 \mathrm{c}$ \\
& Bruno & $0.117 \pm 0.016 \mathrm{a}$ & $0.131 \pm 0.006 \mathrm{a}$ & $0.095 \pm 0.010 \mathrm{a}$ & $0.075 \pm 0.011 \mathrm{~b}$ \\
& Topstar & $0.093 \pm 0.003 \mathrm{c}$ & $0.095 \pm 0.010 \mathrm{c}$ & $0.044 \pm 0.013 \mathrm{ef}$ & $0.053 \pm 0.007 \mathrm{~d}$ \\
& Monty & $0.095 \pm 0.010 \mathrm{bc}$ & $0.107 \pm 0.013 \mathrm{~b}$ & $0.053 \pm 0.012 \mathrm{~d}$ & $0.069 \pm 0.016 \mathrm{bc}$ \\
& Greenlight & $0.069 \pm 0.006 \mathrm{e}$ & $0.084 \pm 0.011 \mathrm{de}$ & $0.089 \pm 0.015 \mathrm{ab}$ & $0.084 \pm 0.006 \mathrm{a}$ \\
& Hayward & $0.096 \pm 0.011 \mathrm{bc}$ & $0.089 \pm 0.019 \mathrm{~cd}$ & $0.073 \pm 0.009 \mathrm{c}$ & $0.059 \pm 0.011 \mathrm{~cd}$ \\
2. Dönem & Bruno & $0.073 \pm 0.006 \mathrm{e}$ & $0.074 \pm 0.004 \mathrm{e}$ & $0.081 \pm 0.013 \mathrm{~b}$ & $0.062 \pm 0.003 \mathrm{c}$ \\
& Topstar & $0.057 \pm 0.008 \mathrm{f}$ & $0.080 \pm 0.010 \mathrm{de}$ & $0.037 \pm 0.017 \mathrm{f}$ & $0.047 \pm 0.007 \mathrm{e}$ \\
& Monty & $0.084 \pm 0.015 \mathrm{~d}$ & $0.064 \pm 0.013 \mathrm{f}$ & $0.051 \pm 0.011 \mathrm{de}$ & $0.030 \pm 0.003 \mathrm{f}$ \\
& Greenlight & $0.069 \pm 0.009 \mathrm{e}$ & $0.047 \pm 0.016 \mathrm{~g}$ & $0.095 \pm 0.010 \mathrm{a}$ & $0.076 \pm 0.007 \mathrm{~b}$ \\
\hline
\end{tabular}

*: Aynı sütun içerisinde aynı harfle gösterilen ortalamalar arasındaki fark 0.05 seviyesinde önemli değildir. 
Yapılan araştırmada incelenen kivi çeşitlerinin siringik asit içerikleri bakımından farklııkları istatistiksel olarak önemli seviyede bulunmuştur. Siringik asit içeriği bakımından çeşitler birbirleriyle kıyaslandığında 1. dönem en yüksek asit içeriğine sahip olan çeşit Bruno $\left(0.117 \mathrm{mg} 100 \mathrm{~g}^{-1}\right)$ çeşidi iken en düşük siringik asit miktarına sahip çeşit Greenlight $\left(0.069 \mathrm{mg} 100 \mathrm{~g}^{-1}\right)$ çeşidi olarak belirlenmiştir. Araştırmada 2. dönem en yüksek siringik asit değerine sahip çeşit Hayward $\left(0.096 \mathrm{mg} 100 \mathrm{~g}^{-1}\right)$ çeşidi iken en düşük siringik asit miktarına sahip çeşit Topstar $\left(0.057 \mathrm{mg} 100 \mathrm{~g}^{-1}\right)$ çeşidi olarak kaydedilmiştir. Greenlight çeşidinde herhangi bir değişim olmazken, 2. dönem hasat edilen diğer çeşitlerde siringik miktarı azalma göstermiştir (Çizelge 3). Çeşitlerin p-kumarik asit düzeyleri kıyaslandığında istatistiksel olarak önemli farklılıklar görülmüştür. Çalışmada birinci dönem p-kumarik asit içeriği bakımından çeşitler karşılaştııılıı̆ında, en yüksek değer Bruno $\left(0.131 \mathrm{mg} 100 \mathrm{~g}^{-1}\right)$ çeşidinde belirlenmiştir. En düşük p-kumarik asit değeri Greenlight $\left(0.084 \mathrm{mg} 100 \mathrm{~g}^{-1}\right)$ çeşidinde saptanmıştır. Araştırmada 2. dönem en yüksek p-kumarik asit içeriğine sahip olan çeşit Hayward $\left(0.089 \mathrm{mg} 100 \mathrm{~g}^{-1}\right)$ çeşidi iken, en düşük p-kumarik asit miktarına sahip çeşit Greenlight $\left(0.047 \mathrm{mg} 100 \mathrm{~g}^{-1}\right)$ çeşidi olarak tespit edilmiştir. Erken hasat edilen meyvelerde (1.dönem) hasat olgunluğuna gelen meyvelere göre p-kumarik asit miktarı daha yüksek bulunmuştur. Yapılan araştırmada incelenen çeşitler ferulik asit düzeyleri açısından karşılaştıııldığında farklılıklar istatistiksel olarak önemli bulunmuştur. Çalışmada ferulik asit düzeyine bakıldığında 1. dönem en yüksek ferulik asit miktarına sahip olan çeşit Bruno $\left(0.095 \mathrm{mg} 100 \mathrm{~g}^{-1}\right)$ çeşidi iken, en düşük ferulik asit içeriğine sahip çeşit Topstar $(0.095 \mathrm{mg} 100$ $\left.\mathrm{g}^{-1}\right)$ çeşidi olarak belirlenmiştir. Araştırmada 2. dönem en yüksek ferulik asit değerine sahip çeşit Greenlight (0.095

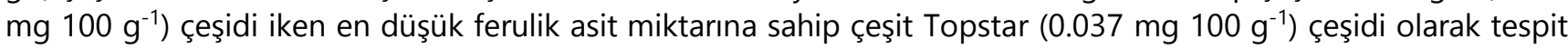
edilmiştir. Greenlight çeşidindeki artış göz önüne alınmazsa, ferulik asit miktarı 2. dönem hasat edilen meyvelerde azalma göstermiştir. İncelenen çeşitler birbirleriyle kıyaslandığında o-kumarik asit içeriğindeki farklılıklar istatistiksel olarak önemli olduğu tespit edilmiştir. İncelenen çeşitler arasında o-kumarik asit miktarı bakımından 1. dönem en yüksek miktara sahip çeşit Greenlight $\left(0.084 \mathrm{mg} 100 \mathrm{~g}^{-1}\right)$ çeşidi iken, en düşük o-kumarik asit düzeyine sahip çeşit Topstar $\left(0.053 \mathrm{mg} 100 \mathrm{~g} \mathrm{~g}^{-1}\right)$ çeşidi olarak ölçülmüştür. Araştırmada 2. dönem en yüksek okumarik asit içeriğine sahip olan çeşit Greenlight $\left(0.076 \mathrm{mg} 100 \mathrm{~g}^{-1}\right)$ çeşidi iken en düşük o-kumarik asit içeriğine

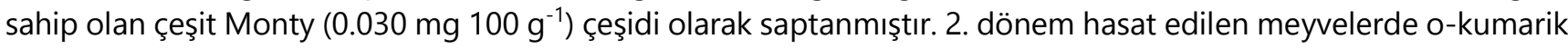
asit miktarı tüm çeşitlerde azalma göstermiştir.

Kivi çeşitlerinde farklı dönemlerde hasat edilen meyvelerin fenolik bileşik içeriklerinin korelasyonları Şekil 1 ve Şekil 2'de verilmiştir. Fenolik bileşikler her iki dönemde benzer korelasyon göstermiştir. Varyasyon 1. dönem hasad edilen meyvelerde \%64.70 düzeyinde oluşurken, 2. dönem hasad edilen meyvelerde \%72.46 olarak elde edilmiştir. Kivi meyvelerinin hasad edildiği her iki dönemde de ferulik asit ile kateşin, siringik asit ile vanillik asit, rutin ile kuersetin ve protokateşuik asit ile klorojeik asit arasında pozitif bir korelasyon sağlanmıştır. Bu pozitif korelasyon ile fenolik bileşik miktarlarının artış ve azalışları açısından birbirlerini olumlu etkilediği görülmüştür. Ancak, yine her iki dönemde de o-kumarik asit ile rutin ve quercetin arasında aksi durum görülmüş ve negatif korelasyon elde edilmiştir.

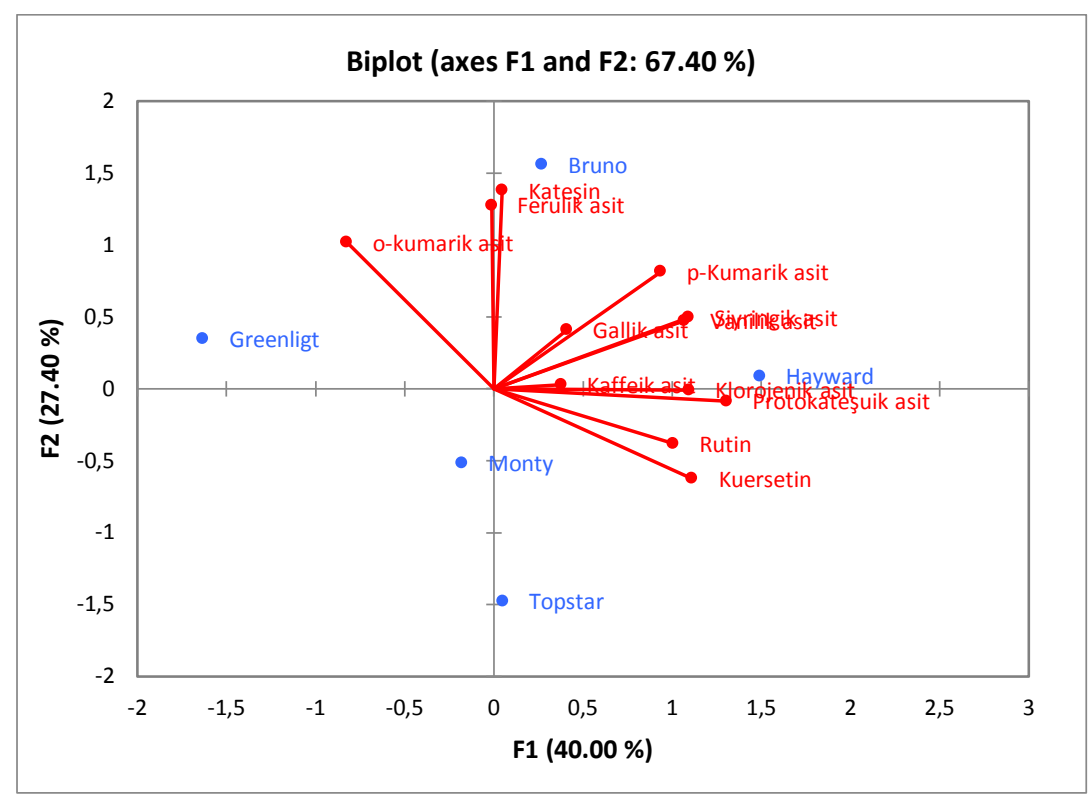

Şekil 1. Kivi çeşitlerine ait meyvelerin fenolik bileşik içerikleri arasındaki korelasyon (1.dönem).

Figure 1. Correlation between the phenolic compounds contents of kiwi cultivars (1st period). 


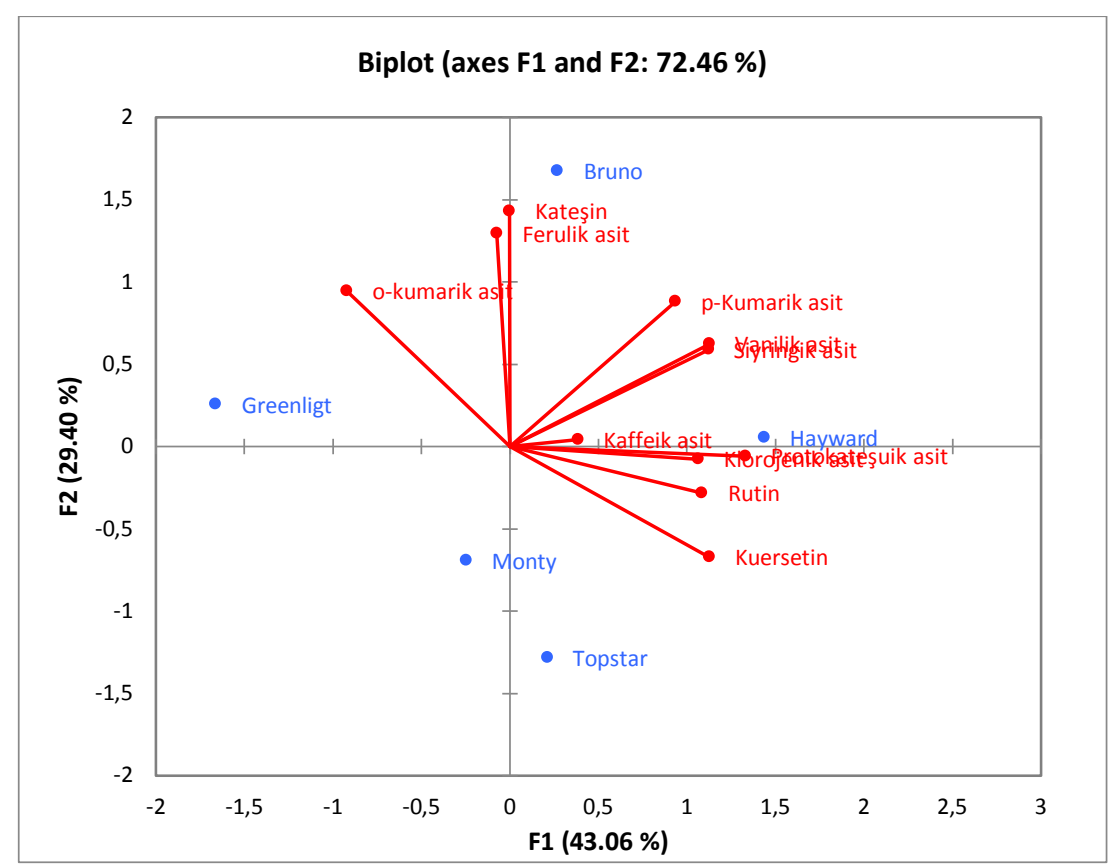

Şekil 2. Kivi çeşitlerinin 1. dönem organik asit bakımından dağılımları.

Figure 2. Distribution of kiwi cultivars in terms of organic acid in 1st period.

Wu ve ark. (2004)'nın yaptıkları çalışmada kivi meyvesinin toplam fenolik madde düzeyi $3.78 \mathrm{mg} \mathrm{GAE} \mathrm{g}^{-1}$ olarak bildirilmiştir. Tavarini ve ark. (2008), yapmış oldukları çalışmada, Hayward kivi çeşidinde belirlenen toplam fenolik madde içeriğini 2.19 GAE g ${ }^{-1}$ olduğunu ifade etmişlerdir. Montanaro ve ark. (2007) yaptıkları bir çalışmada, kivi meyvesinin esas fenolik maddelerinin hidroksisinamik asit, flavonol ve kateşin grubunda yer almakta olduğu ifade edilmiştir. Kim ve ark. (2009) tarafından yürütülen çalışmada, kivi meyvesinin etinde tespit edilen başlıca fenolik maddeler ise kateşin, klorojenik asit, rutin, epikateşin ve kuersetin olarak ifade edilmiştir. Park ve ark. (2011) tarafından yapılan çalışmada, bazı kivi çeşitlerinin fenolik madde dağılımı ilk kez ortaya konulmaya çalışıımıştır. Bu araştırmaya göre kivi meyvesinin başlıca fenolik madde içeriği protokateşik asit olarak bulunmuş ve 14.10- 60.10 $\mathrm{mg} \mathrm{g}^{-1}$ değerleri arasında değiştiği ifade edilmiştir. Ayrıca protokateşik asidi 7.18- $21.70 \mathrm{mg} \mathrm{g}^{-1}$ arasında değer ile kafeik asit, 5.11-7. $15 \mathrm{mg} \mathrm{g}^{-1}$ arasında değer ile vanilik asit ve $2.88-4.05 \mathrm{mg} \mathrm{g}^{-1}$ düzeyleri arasında p-kumarik asidin takip etmekte olduğu araştırmacılar tarafından bildirilmiştir. Tavarini ve ark. (2008) tarafından hasat ve depolama üzerine yapılan çalışmada Hayward kivi çeşidinde antioksidan kapasitesi, askorbik asit, toplam fenoller ve karotenoidlerin değişimi incelenmiş ve hasat zamanı ile depolama arasındaki ilişkide fenolik madde düzeyine etkisi önemsiz bulunmuş ve bu miktarın yaklaşık olarak 35 GAE $100 \mathrm{mg}^{-1}$ ile 65 GAE $100 \mathrm{mg}^{-1}$ arasında değişmiş olduğu ifade edilmiştir. Literatür sonuçları ile çalışmamızı kıyasladığımızda elde edilen verilerin daha yüksek olduğu görülmektedir.

\section{SONUÇ}

Incelenen çeşitlerin fenolik bileşik dağılımlarına bakıldığında çeşitler arasında ciddi farklılıklar saptanmıştır. Bu farklıı̆ın nedeninin çeşit özelliği, kültürel uygulamalar (gübreleme, budama, vb.), yetiştirildikleri bölgenin iklim ve toprak özelliğinden kaynaklandığı düşünülmektedir. Ayrıca olgunlaşma ile birlikte 2. dönem hasat edilen meyvelerde fenolik bileşik miktarında azalma olmuştur. Meyvelerde özellikle buruk tad oluşumuna neden olan fenolik asitlerin azalması göz önüne alınarak hasadın olgunlaşma ile birlikte yapıımasının daha uygun olacağı kanaatine varılmıştır. Özellikle meyve suyuna işleme esnasında sorun oluşturan bu durum dikkate alınmalı, işleme sırasında oluşacak olumsuzlukları azaltacak şekilde hasat yapılmalıdır.

\section{ÇIKAR ÇATIŞMASI}

Yazarlar arasında herhangi bir çıkar çatışması bulunmamaktadır. 


\section{YAZAR KATKISI}

Makalenin yazımı ve analiz işlemleri M.Ş.A, tarafından yürütülmüştür. Konu dizaynı ve yöntem tercihini M.G. planlanmıştır.

\section{TEŞEKKÜR}

Tez çalışması olan bu araştırmada materyal temini konusunda destek veren sayın Dr. Kemal Abdurrahim Kahraman'a, Dr. Erdal Orman'a ve Yalova Atatürk Bahçe Kültürleri Merkez Araştırma Enstitüsü Müdürlüğü'ne teşekkürlerimizi sunarız.

\section{KAYNAKLAR}

Ferguson, A. R., \& Bollard, E. G. (1990). Kiwifruit: Science and Management. Ray Richards Publishing, Auckland.

Funk, C., Braune, A., Grabber, J. H., Steinhart, H., \& Bunzel, M. (2007). Model studies of lignified fiber fermentation by human fecal microbiota and its impact on heterocyclic aromatic amine adsorption. Mutation Research/Fundamental and Molecular Mechanisms of Mutagenesis, 624(1-2), 41-48.

Herralz, T., \& Galısteo, J. (2003). Tetrahydro-b-carboline alkaloids occur in fruits and fruit juices. Activity as antioxidants and radical scavengers. Journal of Agricultural and Food Chemistry, 51, 7156-7161.

Hunter, D., Skınner, M., Ferguson, A., \& Stevenson, L. (2010). Kiwifruit and health. In R. Watson \& V. Reedy (Eds.), Bioactive Foods in Promoting Health: Fruits and vegetables. Atlanta, GA: Elsevier, Inc.

Kim, J.G., Beppua, K., \& Kataokaa, I. (2009). Varietal differences in phenolic content and astringency in skin and flesh of hardy kiwifruit resources in Japan. Scientia Horticulturae, 120(4), 551-554.

Ming, X., Jiang, G. H., Chen, X. X., \& Gao, X. Z. (1991). Selection and breeding of kiwifruit in China. Second International Symposium on Kiwifruit'. Acta Horticulturae, 297(1), 57-60.

Montanaro, G., Treutter, D., \& Xiloyannis, C. (2007). Phenolic compounds in young developing kiwifruit in relation to light exposure: Implications for fruit calcium accumulation. Journal of Plant Interactions, 2(1), 63-69.

Park, Y.S., Leontowicz, H., Leontowicz, M., Namiesnik, J., Suhaj, M., Cvikrova, M., Martincova, O., Weisz, M., \& Gorinstein, S. (2011). Comparison of the contents of bioactive compounds and the level of antioxidant activity in different kiwifruit cultivars. Journal of Food Composition and Analysis, 24(7), 963-970.

Pınellı, P., Romanı, A., Fierını, E., Remorını, D., \& Agati, G. (2013). Characterisation of the polyphenol content in the kiwifruit (Actinidia deliciosa) exocarp for the calibration of a fruit-sorting optical senso. Phytochemical Analysis, 24, 460-466.

Rodriguez-Delgado, M. A., Malovana, S., Perez, J. P., Borges T., \& Garcia-Montelongo, F. J. (2001). Separation pf phenolic compounds by high-performance liquid chromatography with absorbance and fluorimetric detection. Journal of Chromatography, 912, 249-257.

Salıyan, T., Shakheel, M., Satısh, S., \& Hedge, K. (2017). A review on actinidia deliciosa. International Journal of Pharma and Chemical Research, 3(1), 103-108.

Shehata, M. M. S. M., \& Soltan, S. S. A. (2013). Effects of Bioactive Component of kiwi fruit and avocado (fruit and seed) on hypercholesterolemic rats. World Journal of Dairy \& Food Sciences, 8(1), 82-93.

Singletary, K. (2012). Kiwifruit: overview of potential health benefits. Nutrition Today, 47(3), 133-147.

Stonehouse, W., Gammon, C. S., Beck, K. L., Conlon, C. A., Von, Hurst, P. R., \& Kruger, R. (2015). 'Kiwifruit: our daily prescription for health. Natural Health Product Therapies, 1(1), 442-447.

Tavarini, S., Degl"Innocenti, E., Remorini, D., Massai, R., \& Guidi, L. (2008). Antioxidant capacity, ascorbic acid, total phenols and carotenoids changes during harvest and after storage of Hayward kiwifruit. Food Chemistry, 107, 282-288.

TÜiK. (2018). Bitkisel üretim istatistikleri. https://biruni.tuik.gov.tr/medas. Erişim tarihi: 10 Ağustos, 2018.

USDA (2018b). Oxygen radical absorbance capacity (orac) of selected foods, release 2. nutrient data laboratory home. http://www.orac-info-portal.de/download/ORAC_R2.pdf. Erişim tarihi: 5 Ağustos, 2018.

Witschı, A., Reddy, S., Stofer, B., \& Lauterburg, B. (1992). The systemic availability of oral glutathione. European Journal of Clinical Pharmacology, 43, 667-669.

Wu, X., Beecher, G. R., Holden, J. M., Haytowitz, D. B., Gebhardt, S. E., \& Prior, R. L. (2004). Lipophilic and hydrophilic antioxidant capacities of common foods in the United States. Journal of Agricultural and Food Chemistry, 52, 4026-4037. 
Şahin Kanbur ve Gündoğdu, Kivi Meyvelerinin Olgunlaşma Evrelerine Göre Fenolik Bileşik İ̧̧eriklerindeki Dağılım

Yalçın, T. (1999). Kiwi Yetiştiriciliği. Atatürk Bahçe Kültürleri Merkez Araştırma Enstitüsü, Yayın No: 76, Yalova. 